\title{
Landscape structure and food supply affect eagle owl (Bubo bubo) density and breeding performance: a case of intra-population heterogeneity
}

\author{
Vincenzo Penteriani', Max Gallardo ${ }^{2}$ and Philip Roche ${ }^{3}$ \\ ' Department of Applied Biology, Estación Biológica de Doñana, C.S.I.C., Avda. de Maria Luisa s/n., Pabellón del Perú, Apdo I056, 4I0I3 \\ Seville, Spain \\ ${ }^{2}$ Parc Naturel Régional du Luberon, 60 place Jean Jaurès, BP I22, 84404 Apt, France \\ ${ }^{3}$ Institut Méditerranéen d'Ecologie et de Paléoécologie, Université d'Aix-Marseille, FST St Jerome, Case 46I, I3397 Marseille, France
}

\begin{abstract}
Abztrast
During the 20th century, Mediterranean landscapes underwent extensive changes. In particular, decreasing grazing pressure combined with abandonment of agricultural uplands favoured the development of Mediterranean forests with a corresponding reduction of open habitats and landscape diversity. In some parts of the Mediterranean basin, including our study area, the reduction of open landscapes took place at the same time as a rapid decline in rabbits as a result of myxomatosis. This study assesses the impact of past changes in landscape and rabbit density on the density and the breeding performance of the eagle owl Bubo bubo, one of the largest predators of Mediterranean ecosystems. Eagle owl density, nest site structure and composition at the landscape level, diet and fecundity of 35 eagle owl nesting territories was analysed for 27 years. The study area is characterized by two distinct areas, the border of the massif and the interior, in which past changes acted differently. Eagle owls in the interior were simultaneously affected by the loss of rabbits, a shift to smaller prey, and by open areas reverting to forest. All of these factors reduced the foraging efficiency of the owls. When myxomatosis decimated the rabbit population, owls in the border area switched to other mammals, birds and fish, whereas in the interior, alternative prey were less abundant. The main impacts of reduced prey availability and landscape diversity on interior pairs were: (I) lower density of breeding pairs; (2) lower diversity in landscape structure and closer habitats; (3) lower richness and diversity in the diet; (4) later egg-laying dates; (5) lower productivity.
\end{abstract}

Łey wordz: Bubo bubo, eagle owl, intra-population heterogeneity, landscape structure, food supply

\section{INTRODUCTION}

The relationships between the results of past habitat change and species responses, resulting in possible intrinsic variances in reproductive parameters within the same population, represent one of the most challenging problems for ecology (Lrebs, 1991). Long-term studies on birds can yield useful empirical evidence about such changes: Gerrodette (1987) provides examples in which 10-20 years of data were required to recognize species' response to habitat changes. Long-lived species may be used as bio-indicators of environmental change and studied to test hypotheses about ways in which they respond and adapt to changes. Moreover, raptors should be considered key species in landscape resource management, given their position towards the top of the food chains and their fundamental role in ecological processes.

*All correspondence to: Vincenzo Penteriani

E-mail: penteriani@ebd.csic.es
The eagle owl Bubo bubo is widely distributed across Europe, Asia and North Africa (Mikkola, 1994; Penteriani, 1996). It inhabits a large variety of habitats from boreal coniferous and mixed deciduous forests to Mediterranean scrub and steppes and rocky and sandy deserts (Mikkola, 1994; Penteriani, 1996), although its most characteristic hunting habitat is open land (Leditznig, 1992, 1996; Penteriani, 1996). The eagle owl is, together with the Spanish imperial eagle Aquila adalbevti, the most specialized rabbit Ovyctolagur cuniculur predator among large European raptors (Delibes \& Hiraldo, 1979), and reaches peak abundance in typical and cold Mediterranean regions where rabbits are widespread and abundant (Donázar, 1987).

The general trend of the landscape changes in our study area, in common with most countries in the Mediterranean basin, is toward disruption of the formerly human-maintained agro-pastoral equilibrium that contributed to the biological diversity of these seminatural landscapes (Naveh \& Liebermann, 1994; 
Blondel \& Aronson, 1999). In particular, decreasing grazing pressure combined with abandonment of agricultural uplands favoured the development of Mediterranean forests (e.g. Quevcur ilex) and a correspondent rapid reduction of open areas and landscape diversity (M. Gallardo \& M. Guende, pers. obs.). In Provence, because of the considerable process of land abandonment, a general increase of forested areas (e.g. matorrals, pine woods) occurs at the expense of open vegetation such as lawns, fallows and crops (Barbero et al., 1990). This dereliction of formally cultivated and grazed lands induces changes in landscape patterns and dynamics. CEFAC (1988), Baudry \& Tatoni (1993) and SIG Luberon (2000) noted that in the interior areas of the Luberon mountain crops area surfaces were about seven times smaller than a century ago, while forested area surfaces increased by $50 \%$ as did the landscape connectedness.

Moreover, since 1936, rabbit populations in our area have declined due to myxomatosis. In the interior area, this phenomenon was severe (about two-thirds of the population disappeared, Gallardo, Austruy et al., 1987), and the density of eagle owls consequently declined in the years following the crash in the rabbit population (Gallardo, Austruy et al., 1987). Rabbits comprised $>60 \%$ of the overall prey biomass in several eagle owl territories occupied before the onset of myxomatosis and deserted afterwards (Gallardo, Austruy et al., 1987; M. Gallardo, pers. obs.). Similar responses of eagle owls to myxomatosis were observed elsewhere in France (Choussy, 1971).

In this paper, the impact of the past changes in landscape structure and rabbit density on the breeding performance of one of the largest predators of Mediterranean ecosystems is assessed. It is hypothesized that past changes acted differently in the massif, creating heterogeneity in the landscape features (and in the potential prey species composition) and a consequent heterogeneity in breeding performance within the same population. This study is unique because within our study area it is possible to identify, along a vertical gradient, two successive horizontal levels (spaced from 2 to $4 \mathrm{~km}$ ) with morphological, landscape structure and land-use pattern differences resulting from changes that occurred in the past. The difference in altitude of the nest sites between the two levels was irrelevant because they were $300 \mathrm{~m}$ a.s.I. (maximum), and the eagle owl habitually hunts mainly near the nest (Frey, 1973; Leditznig, 1996), which allowed us to discriminate these two subsamples of the overall massif population (Penteriani, Gallardo, Roche et al., 200l), and to evaluate their response to different prey and landscape structures.

\section{MATERIAL AND METHODF}

Ftudy area

The study was conducted from I97I to 1999 in a Mediterranean area of southern France (Luberon, Provence region). The area falls in the humid Mediterranean climatic zone (Donázar, 1987) with elevations ranging from 160 to $700 \mathrm{~m}$. The area was split into 2 along a vertical gradient on the basis of morphology, landscape structure and land use patterns (Penteriani, Gallardo, Roche et al., 200l). The lower 'border' area consists of the piedmont mountains and of the Durance river valley, characterized by intense human activity. The landscape comprised open areas (croplands, pastures and fallow lands) along the riverside and Mediterranean forests (Quevcur ilex, Q. pubercenr and Pinur halepenrir) and some garrigue patches. Rocky areas are scattered through the border, with several isolated small cliffs. The 'interior' area (at a higher elevation) comprised more 'natural' valleys with a mosaic structure of large rocky canyons, overhanging garrigues (mainly Quevcur coccifeva, Thymur rulgavir and Rormavinur officinalir), and Mediterranean forest. The forest expansion started in the early 1900s, mainly as a result of the decrease in grazing pressure from livestock (M. Gallardo, pers. obs.).

\section{Cenzuz of breeding pairz}

Eagle owl nest sites were identified using a combination of methods, including: (I) searching rock areas that were mapped (l:25 000) and searches of cliffs, the sizes of which were too small to be shown on topographic maps; (2) visiting (October-February, May-July) cliffs to detect nests, pellets, and feeding perches; (3) passive auditory surveys at sunrise and sunset, from October to February, when the vocal activity of adults was most intense (Bergerhausen \& Willelms, 1988; Penteriani \& Pinchera, I99la,b); (4) passive auditory surveys of calling young, from when chicks were $c$. 30 days old until a month after leaving the nest (May-June in our study area). The listening sessions for calling young took place during the day (Penteriani, Gallardo \& Cazassus, 2000) and night (Lranz, I97I; Mysterud \& Dunker, 1982). Listening sessions for adults and young were also undertaken in valleys without cliffs, because some nests were found in rockless areas in Provence (Blondel \& Badan, 1976). Suitable nest sites were considered unoccupied only after a complete walking search and 3 negative adult listening sessions (Bergerhausen \& Willelms, 1988; Penteriani \& Pinchera, I99la,b). The nearest neighbour distance (NND) method (Newton et al., 1977) was used to estimate density. Regularity of nest spacing was computed by means of the G-test (Brown \& Rothery, 1978), calculated as the ratio between the geometric and the arithmetic mean of the squared NNDs. The index ranges from 0 to $\mathbf{I}$; values $>$ 0.65 indicate a uniform distribution of nests.

In the statistical analyses, an eagle owl nest site was considered to be in the border or interior area when clearly inside I of these altitude bands.

\section{Nezting habitat analyziz}

Discriminant function analysis (DFA) was used to test for possible differences in nest site structure and compo- 
sition at the landscape level between the border $(n=22)$ and interior $(n=13)$ pairs. $A z^{2}$ analysis tested the significance of the site classification established by the DFA procedure (Sokal \& Rohlf, 1995). The analysis of landscape features was based on circular plots centred on the nest site, with a radius of $1000 \mathrm{~m}$. This scale was chosen because: (I) eagle owls prefer to nest near their favourite hunting grounds (Frey, 1973; Olsson, 1979; Donázar, 1988; Donázar, et al., I989; Leditznig, 1992); (2) breeding success is influenced by the distance from nest to foraging areas (Leditznig, 1996). The landscape was analysed with the IDRISI program (geographical information system, GIS), using a land cover layer and a digital elevation model (DEM) layer with a horizontal resolution of $50 \mathrm{~m}$. A 1996 Landsat 4 scene was classified using an unsupervised classification procedure with 25 classes. The classes were identified from vegetation maps and field surveys. The initial classes were aggregated into 4 land-cover elements defined by both the density of vegetation cover and the nature of the woody vegetation: the resulting landscape elements represent more the structure of the vegetation than the nature of the dominant species. An overall set of 8 variables was used to describe the nest site: 4 variables described land cover categories (percentage of open land, shrubs, woodland, and river) and 3 variables described horizontal heterogeneity (ecotone number, calculated along 2 orthogonal axes from the plot centre; proximity index, mean distance of the plot centre from open land; Shannon diversity index), and minimum distance of the nest from the nearest patch of open land. These variables have been used previously in the analysis of the eagle owl nesting habitat (e.g. Donázar, 1988; Donázar, Ceballos \& Leon, 1989) and proved to be important in the description of the eagle owl nest site structure in our area (Penteriani, Gallardo, Roche et al., 200I).

\section{Diet analyziz}

Diet was determined by repeated visits in the overall period of the breeding performance study to 27 nest sites to collect prey remains and pellets and by direct observations at sunset and sunrise. The combination of different methods to determine diet may yield more accurate estimates of the overall diet than using just I method (Rosenberg \& Cooper, 1990; Simmons, Avery \& Avery, 199l). Prey remains and pellets were identified by macroscopic comparison with reference collections. Live biomass was estimated using direct measurements, mass data from the study area and bibliographic sources (Géroudet, 1946-57). The contribution of each preygroup to overall biomass was calculated by multiplying the proportion of each group by the mean body mass of individuals in the group. Pellets from individual visits were pooled into a single sample for analysis. The presence of different prey types in the samples was recorded, but no attempt was made to quantify the number of individuals. To avoid duplication of prey, i.e. in remains and pellets, items found in pellets were used only if they had not been found as remains during the same visit (Penteriani, 1997).

We analysed differences in diet between the border and the interior pairs by:

(I) vichnerr (number of identified prey species in the diet, Magurran, 1988);

(2) direvrity, measured by the Shannon index (Magurran, 1988):

$$
\mathrm{H}^{\prime}=-Z \mathrm{p}_{\mathrm{i}} \ln \mathrm{p}_{\mathrm{i}}
$$

where $p_{i}$ is the proportional abundance of the ith species $=n_{i} / N$; a t test was used to test for differences in the diversity of the 2-sample (border rr interior);

(3) erenerr, the ratio of observed diversity to maximum diversity:

$$
\mathrm{E}=\mathrm{H}^{\prime} / \mathrm{Inn}
$$

where $\mathrm{H}^{\prime}$ is the Shannon index and $\mathrm{n}$ is the total number of prey species (Magurran, 1988). $E$ is constrained between 0 and I, with I representing a situation in which all species are equally abundant;

(4) DFA was used to test for differences in diet composition between border and interior pairs, and to identify prey species or groups that best contributed to distinguish the owl pairs breeding in the 2 sectors of the study area. A $z^{2}$ analysis tested the significance of the accuracy of site classification (border or interior) established by the DFA procedure. Ten variables were used to describe the diet: percentages of bird biomass, pigeon/dove biomass, crow biomass, mammal biomass, hedgehog biomass, rabbit biomass, rat biomass, fish biomass, richness, and Shannon diversity index.

\section{Produstirity analyziz}

Thirty-five different nesting sites were checked for 27 years (23 nest sites were in the border area, 12 in the interior). Each nest was visited several times, but mainly during 2 periods: (I) the pre-laying period (from October to mid-February) to check for occupancy; (2) the nestling (starting when chicks were c. 2-3 weeks old) and the fledgling period (until August). Laying date was calculated by subtracting 35 days from the date of hatching (Penteriani, 1996), and hatching date was calculated by backdating nestling on the basis of feather development, using personal observations at focal nests and information in Cramp \& Simmons (1985) and Glutz von Blotzheim \& Bauer (1980). The fledging date (defined as the time when the young leave the nest) was not calculated because it depends on the morphology of nesting cliffs: the more vertical the cliff, the later the young fledge (V. Penteriani, pers. obs.). Following the terminology proposed by Steenhof (1987), a breeding pair was I that laid eggs, and a successful pair was I that fledged at least $\mathbf{I}$ young. Three measures of breeding success were used: the percentage of nests that 
fledged at least I chick, and the mean number of young fledged per breeding and per successful pair. We used the mean number of young to avoid pseudoreplications because it was not possible to check the productivity for each territory each year. Analysis of variance (ANOVA) was used to detect differences between years in the mean number of young fledged per breeding pair or per successful pair (Sokal \& Rohlf, 1995). The mean number of young per breeding and per successful pair was compared between border and interior pairs by means of Mann-Whitney U-tests.

The effect of landscape structure and food supply on NNDs and the mean number of fledged young per breeding pair were examined by stepwise multiple regression analysis (Norusis, 1993; Sokal \& Rohlf, I995). Relationships between structure and composition of the landscape surrounding the nest cliff, diet characteristics and productivity were investigated with Spearman rank correlations. Both multiple regression analysis and correlations were run on a sub-sample of 27 nest sites, for which the overall set of data (nesting habitat, diet and productivity) were collected: 18 out of the 27 nest sites were in the border area. When data were not normally distributed, they were transformed (Sokal \& Rohlf, 1995). When multiple comparisons were carried out on a set of values, the sequential Bonferroni correction was used to adjust the significance level (Rice, 1989). All means are given $\pm \mathrm{sa}$, all tests are 2-tailed, and statistical significance was set at $P<0.05$. The software package used was SPSSIO.0.

\section{REFULTF}

\section{Denzity}

A total of 59 eagle owl nesting territories was identified, with an overall density of 15.3 occupied territories/ $100 \mathrm{~km}^{2}$. The mean distance between territories averaged $1770 \mathrm{~m}$ (range $=700-4300 \mathrm{~m}, \mathrm{sa}=970.6 \mathrm{~m}$ ) and these were regularly distributed (G-statistic $=0.74$ ).

There was a significant difference in density between the two sectors of the study area, a progressive and significant bottom-up decrease was observed $\left(z^{2}=138.6\right.$, d.f. $=\mathbf{I}, \mathrm{P}=0.00 \mathrm{l})$. In the border area (3l.6 nest sites/ $100 \mathrm{~km}^{2}$ ), the mean NND was $1353 \mathrm{~m}$ (range $=700$ $3000 \mathrm{~m}$, sa = 828), and the value of the G-statistic (0.75) showed a uniform dispersion. In the interior area (19.6 nest sites $/ 100 \mathrm{~km}^{2}$ ), the mean NND was $1808 \mathrm{~m}$ (range $=800-3500 \mathrm{~m}, \mathrm{sa}=960.5 \mathrm{~m}$ ), and the value of the G-statistic (0.77) showed uniform nest dispersion.

Two variables met the entrance criteria of a stepwise multiple regression model, using NNDs as a dependent variable $\left(R^{2}=0.74\right)$ : percentage of birds in the diet biomass $(B=-106.56, \quad p=-0.79, \quad t=-7.6 \mid$, $\mathrm{P}=0.000 \mathrm{I})$ and distance to the nearest openland $(B=6.72, p=0.28, t=2.65, P=0.0 l)$. The increase of the NNDs between reproductive sites was positively correlated with the distance from the massif border $\left(v_{s}=0.78, P=0.0001, n=27\right)$.
Table 1. Characteristics of the structure and composition of the landscape surrounding eagle owl nest sites (within a radius of $1000 \mathrm{~m}$ around the nest) in southern France (Luberon massif): $\operatorname{border}(n=22) \operatorname{rr}$ interior $(n=13)$

\begin{tabular}{|c|c|c|}
\hline Variable & Border (mean \pm sa) & Interior (mean $\pm \mathrm{sa})$ \\
\hline Open land (\%) & $35.6 \pm 16.1$ & $29.1 \pm 19.9$ \\
\hline Shrubland (\%) & $29 \pm 13.5$ & $33.7 \pm 10.5$ \\
\hline Woodland (\%) & $34.5 \pm 18.9$ & $37.3 \pm 15.2$ \\
\hline River (\%) & $0.8 \pm 1.2$ & $0 \pm 0$ \\
\hline Ecotone number & $13.3 \pm 1.6$ & $13.2 \pm 1.5$ \\
\hline \multicolumn{3}{|l|}{$\begin{array}{l}\text { to the nearest } \\
\text { patch of open }\end{array}$} \\
\hline land (m) & $29.7 \pm 32.2$ & $44.9 \pm 56.6$ \\
\hline Proximity index & $59 \pm 34.6$ & $65.8 \pm 46.5$ \\
\hline \multicolumn{3}{|c|}{ Shannon diversity } \\
\hline index & $1.7 \pm 0.2$ & $1.8 \pm 0.2$ \\
\hline
\end{tabular}

\section{Nezting habitat}

Within a radius of $1000 \mathrm{~m}$ around the nest, the DFA significantly discriminated $(P<0.05)$ the border from the interior sites (Table I). These differences were based on four variables: percentage of open land ( $>$ in the border area), percentage of river ( $>$ in the border area), minimum distance to the nearest patch of open land ( $<$ in the border area), and Shannon diversity index (lower in the border area). The discriminant equation was represented by $\mathrm{D}=4.304+0.033$ (\% of open land) +1.083 (\% of river) +0.350 (minimum distance to the nearest patch of open land) -6.003 (Shannon diversity index). With DFA, a correct classification was obtained for $18(81.8 \%)$ of the border nest sites and six (46.2\%) of the interior nest sites; $71.4 \%$ of the originally grouped cases were correctly classified. This classification was non-random $\left(z^{2}=11.98, P=0.02\right)$. There was a positive relationship between the percentage of woodland around nests and distance to open land $\left(v_{s}=0.53\right.$, $P=0.004, n=27)$.

\section{Diet analyziz}

A total of 2149 prey items was identified from pellets, prey remains and direct observations; 1330 prey items were collected at border and 819 at interior nest sites.

The comparison between the diet of eagle owls in the border and interior showed that the diet of pairs in the border included 70 identified prey species, whereas it included only 32 identified prey species in the interior, i.e. diet-richness of border pairs was higher. Moreover, diet-richness was negatively correlated with the distance from the border $\left(v_{s}=-0.83, P=0.000 I, n=27\right)$; i.e. eagle owls from the margin of the massif may shift more easily from one prey species to another.

In the border, birds represented $29.5 \%$ of the prey items and $12.6 \%$ of the biomass, whereas in the interior these figures are $17.2 \%$ and $9 \%$, respectively. The difference in border $\mathrm{rr}$ interior biomass percentage was 
significant $(Z=-4.17 \mathrm{I}, \mathrm{P}=0.000 \mathrm{I}$, Mann-Whitney $\mathrm{U}$ test).

In the border, mammals represented $61 \%$ of the prey items and $65.5 \%$ of the biomass, compared to $80.9 \%$ and $88.3 \%$, respectively, for the interior. The difference in border $\mathrm{rr}$ interior biomass percentage was significant ( $Z=-4.173, P=0.000$ l, Mann-Whitney U-test).

Fish represented $7.6 \%$ of the items and $9.9 \%$ of the biomass in the border, compared to $1.7 \%$ and $1.2 \%$, respectively, for the interior. The difference in border $\mathrm{rr}$ interior biomass percentage was significant $(Z=-4.182$, $\mathrm{P}=0.000 \mathrm{l}$, Mann-Whitney U-test).

Crows represented the main bird group and rats the main mammalian prey in both border (frequency $=7.6 \%, \quad$ biomass $=4.6 \%$ ) and interior (frequency $=5.6 \%$, biomass $=3.2 \%$ ) diets. For the other two main prey mammals, rabbits and hedgehogs, the percentages in the border (rabbit frequency $=5.1 \%$, rabbit biomass $=14.6 \%$; hedgehog frequency $=5.1 \%$, hedgehog biomass $=13.7 \%$ ) were lower than in the interior (rabbit frequency $=13.5 \%$, rabbit biomass $=$ $29.3 \%$; hedgehog frequency $=8.2 \%$, hedgehog biomass $=16.3 \%)$. The Shannon diversity index was higher in the border diet $\left(\mathrm{H}^{\prime}=2.325\right)$ than in the interior one $\left(H^{\prime}=1.935\right) \quad(t=4.80 l$, d.f. $=88, P<0.00 l)$, and the evenness values were similar: 0.55 for the border diet, and 0.56 for the interior diet.

The DFA significantly discriminated $(P<0.05)$ the border $(n=18)$ diet from that of the interior $(n=9)$. These differences were based on seven variables: percentage of bird biomass, crow biomass, mammal biomass, rabbit biomass, rats biomass, fish biomass, and Shannon diversity index. A correct classification was obtained for all border and interior nest sites (I00\%). This classification was non-random $\left(z^{2}=159.56\right.$, $\mathrm{P}<0.000 \mathrm{l}$ ).

Attributing each prey species to the category 'open land' or 'woodland', the contribution of open land to the diet was $82 \%$ in terms of prey items and $91 \%$ in term of biomass in the border nesting sites, and $81.4 \%$ and $94 \%$, respectively, in the interior nesting sites.

\section{Phenology and produstirity}

The mean egg-laying date was 16 February $\pm \mathbf{I 5}$ days (minimum 25 December, maximum 20 March, $n=107$ ); $48.1 \%$ of clutches were laid between II and 20 February. Egg-laying date was positively correlated with the distance to the border area $\left(v_{s}=0.72, P=0.0001, n=27\right)$ and with the percentage of mammals in the diet biomass $\left(v_{s}=0.5 \mathrm{I}, \quad P=0.006, n=27\right)$, but negatively correlated with the percentage of fish biomass in the diet $\left(v_{s}=-0.54, P=0.004, n=27\right)$, and with diet diversity $\left(v_{s}=-0.66, P=0.0001, n=27\right)$.

No significant differences between years were detected for either the mean number of fledged young per breeding pair $\left(F_{26,320}=1.202, \quad P=0.23 l\right)$ or per successful pair $\left(F_{26,279}=1.166, P=0.268\right)$. The mean number of fledged young per breeding pair was
$1.79 \pm 0.75$ in the border area and $1.52 \pm 0.73$ in the interior $(Z=-3.017, P=0.003$, Mann-Whitney U-test). The mean number of fledged young per successful pair was $1.9 \pm 0.62$ in the border area and I.69 \pm 0.55 in the interior ( $Z=-2.7 \mathrm{I}, \mathrm{P}=0.007$, Mann-Whitney U-test).

The number of fledged young was positively affected by the percentage of open land within a radius of $1000 \mathrm{~m}$ around the nest site $\left(\mathrm{R}^{2}=0.57, \mathrm{~B}=0.0 \mathrm{l}\right.$, $p=0.55, t=3.27, P=0.003)$ : in the nesting sites surrounded by larger quantities of open habitat (i.e. the main hunting territory), the production of young was higher than in the nesting sites within the more forested landscape. The frequency of breeding attempts that produced three young was positively correlated with the percentage of open land within a radius of $1000 \mathrm{~m}$ around the nest $\left(v_{s}=0.39, P=0.02, n=27\right)$ and the dietrichness $\left(v_{s}=0.38, P=0.02, n=27\right)$. The breeding attempts that produced one young were negatively correlated with the percentage of open land $\left(v_{s}=-0.4 \mathrm{I}\right.$, $P=0.04, n=27$ ).

\section{DIFCUFFION}

In some parts of the Mediterranean basin, including our study area, two main contemporaneous changes occurred: the reduction of open landscapes and the rapid decrease of rabbits as a result of myxomatosis. Rabbits are the main prey of the Mediterranean eagle owls (Bayle, Orsini \& Boutin, 1987; Donázar, 1987) and their decline produced a severe food shortage. Voous (1988) considered the eagle owl had become a bird of the past, designed to hunt medium- to large-sized mammals, but forced to turn to small mammals and medium-sized birds in a large part of its range. Our results indicate that, under several conditions, eagle owls have adapted relatively well to the changing Mediterranean landscape, being able to shift to other prey species and maintain stable populations, but with density and breeding success lower than in areas with high rabbit abundance (Blondel \& Badan, 1976; Donázar, 1987). Indeed, eagle owl pairs with a diet based largely on high-value foods (e.g. rabbits and rats) bred earlier and produced large broods (Cochet, 1999), showing an increase in breedingeffective numbers (Donázar, 1990), even though it is an opportunistic hunter (Olsson, 1979; Mysterud \& Dunker, 1982) with the highest degree of diversity and food-niche breadth value among owls (Herrera \& Hiraldo, 1976).

Animal populations are frequently considered as a unique entity characterized by homogeneous responses to stresses or alterations. However, it is clear that these might work as more complex systems and be composed of sub-units characterized by a high intrinsic variance (Ferrer \& Donázar, 1996). In our study area, the density and reproductive performance of the eagle owls in the border area were higher than in the interior lands, although both are separated by no more than $4 \mathrm{~km}$. For example, egg-laying date was positively correlated with the distance to the massif border (where the diet richness 
and diversity were higher), and to the diversity of diet. Birds that lay eggs earlier in the reproductive season are typically in better physical condition than the ones that lay later (Pierotti \& Annett, 1987). Moreover, the breeding pairs in the interior were highly specialized in hunting rabbits during the early 1900 s (Gallardo et al., 1987; M. Gallardo, pers. obs.), because of the abundance of these lagomorphs in the inland maquis until 1936, and they probably suffered more from the rabbit decrease than eagle owl pairs in the border. The reduced diversity and richness of the eagle owl diet in the interior $\mathrm{rr}$ the one in the border (probably also a result of the more closed landscape), as well as the higher percentage of mammals (especially rats, rabbits and hedgehogs) in the diet, led to a higher trophic specialization of the interior owls, and consequently to difficulties in replacing prey of such a high nutritional value as the rabbit. Actually, the separation of the two diets (border $\mathrm{rr}$ interior) by DFA was very high. We might hypothesize that, when myxomatosis struck the population of rabbits, the pairs in the border found in other mammals, birds and fish a good substitute for these lagomorphs, whereas in the interior, the more closed habitats and the low landscape diversity made this adaptation more difficult. Another sign of the heterogeneous structure of this eagle owl population is represented by the increasing NND values from the border to the interior.

Birds and fish are subordinate prey in Mediterranean regions characterized by a high density of rabbits (Donázar \& Ceballos, 1984; Bayle et al., 1987), but in our study area, as well as in areas with decreasing rabbit populations (Donázar \& Ceballos, 1984), their contribution to the diet partially offset the loss of the lagomorph. The shift from rabbit prey to other prey species (in particular birds) is a peculiar characteristic of our population affected by an important rabbit decrease, because in the neighbouring areas richer in rabbits, the percentages of birds in the eagle owl diet were always lower than in our study area (Blondel \& Badan, 1976; Orsini, 1985; Bayle et al., 1987; Seriot, 1987; Penteriani, 1996). As pointed out by Donázar (1987), when rabbits have low densities and a fragmented spatial distribution, the eagle owl is forced to supplement its diet with prey of less nutritional value: the percentages of rats and hedgehogs (the other two main prey species) were higher in the diet of the interior eagle owl, but this was not sufficient to offset the decrease in rabbits, as often occurs in this species (Orsini, 1985). Optimal foraging theory predicts that dietary changes occur as soon as the more profitable food item becomes available or the main prey density decreases until a threshold is reached, beyond which the intake of energy per unit of time is not maximized (alternative prey hypothesis; Lamil, Lrebs \& Puliam, 1987; Pierotti \& Annett, 1987). This switch might be expected not only because the adults are selected to prefer a food supply of high value, but also because selection would favour parent birds that take food that enhances the chance of offspring survival. The observed switching in the eagle owl diet fits well with the predic- tion of optimal diet theory: as a high-ranked food item (rabbit) decreases in abundance, lower ranking food items (e.g. smaller mammals, birds and fishes) will make up part of the diet more frequently (Lamil \& Sargent, I98I; Lamil et al., 1987).

The importance of rabbits for Mediterranean eagle owls is also highlighted by instances of partial extinction, or a decrease in productivity, in areas experiencing rabbit decline as a result of myxomatosis (Choussy, 197I; Purroy, 1974; Martinez et al., 1992), as well as by the expansion of eagle owl populations when there is an increase in the number of rabbits (Bergier \& Badan, 1979; Cheylan, 1979). Note that the NNDs were negatively correlated with the percentage of bird biomass in the diet, and the egg-laying date was positively correlated with the percentage of mammals in biomass and negatively correlated with the percentage of fish biomass and diet diversity. This probably means that, after the decrease in the rabbit population, the other mammalian species (with less nutritional value or more scattered distribution) did not completely offset this decrease in the interior, whereas the pairs in the border found better food substitutes in the more varied landscape.

The present situation of the eagle owl pairs breeding in the border of the massif seems to be similar to that in the eastern sectors of Navarre (Donázar \& Ceballos, 1984), where the abundance of rocky areas and substitute prey (rats, hedgehogs and birds) preserved a fairly abundant population of eagle owls. Richness and diversity in the diet of border eagle owls are higher than in the interior: this phenomenon is typical of the substitution of small prey (small mammals, birds and fish) for rabbits (Donázar, 1987), and is a common tendency for large predators such as golden eagle Aquila chvyraetor, imperial eagle, Bonelli's eagle Hievaaetur farciatur, and lynx Lynx pavdina in other Mediterranean areas (Calderón, Delibes \& Amores, 1980; Delibes, 1980; Alamany et al., 1984; Garzón et al., 1984). Moreover, higher percentages of forest patches near the nest cliff (as evidenced by the DFA for the interior sites, where the landscape was more closed than in the border) increased the distance from open land (the preferred hunting territory of the eagle owl, as pointed out in this study and by Bochenski, 1960; Olsson, 1979; Obuch \& Rybin, 1993; Leditznig, 1996; Simeonov, Milchev \& Boev, 1998), intensifying the effect of the rabbit shortage.

We hypothesize that when the eagle owls in the interior were simultaneously affected by the loss of a high-value prey (and the consequent shift to smaller prey leading to loss of hunting efficiency) and by the closing of the landscape, they were forced to expend more energy to obtain food (Valverde, 1967; Schoener, 1971). Our results are consistent with Leditznig (1996), who showed that the more forested the home range, the lower the reproductive success, primarily because of reduced prey abundance and availability: the number of fledged young was positively correlated with the amount of open land surrounding the nest site. As shown by our 
results, and as pointed out by Leditznig (1996), the distance between the nest cliff and the open areas seems to be related to the breeding success. The positive relationship between the NNDs and the distance to the nearest openland also evidenced the importance of open land for the species.

The effects on interior eagle owls of prey availability and landscape structure, as stressed by our study, may be summarized as: (I) lower density of breeding pairs; (2) lower diversity in landscape structure and closer habitats; (3) lower richness and diversity in the diet; (4) later egg-laying dates; (5) lower productivity. The values of density and productivity for the overall Luberon massif (border plus interior breeding pairs) were lower than the ones for the Alpilles massif (Blondel \& Badan, 1976), a mountain very close to our study area (the Durance River represents the borderline between them), but characterized by high rabbit densities.

\section{Asknowledgementz}

We are indebted to F. Liberatori, M. Melletti, C. and $\mathrm{P}$. Horisberger, $\mathrm{H}$. Magnin and $\mathrm{O}$. Malbec for their invaluable help in the various stages of this study. P. Bayle, G. Marangoni, P. Orsini and E. Vialet helped us in the prey determinations. E. Alleva and D. Santucci gave us optical instruments to allow nocturnal observations. We thank J. A. Donázar, M. Ferrer, P. Galeotti, S. J. Petty, S. Saraceni, F. Sergio, G. A. Sonerud and an anonymous referee for constructive comments on an early draft of the manuscript. During the study VP received a research grant from the Regional Park of Luberon and a post-doctoral grant from the Estación Biológica de Doñana/Consejo Superior de Investigaciones Científicas.

\section{REFERENCEF}

Alamany, O., De Juan, A., Parellada, X. \& Real, J. (1984). Status de l'aliga cuabarrada (Hievvaetur farciatur) a Catalunya. Rapinyaiver Meditevvanir 2: 98-I08.

Barbero, M., Bonin, G., Loisel, R. \& Quezel, P. (1990). Changes and disturbances of forest ecosystems caused by human activities in the western part of the mediterranean basin. Vegetatio 87: $151-173$.

Baudry, J. \& Tatoni, T. (1993). Changes in landscape patterns and vegetation dynamics in Provence, France. Landrcape Uvban Plann. 24: I55-I59.

Bayle, P., Orsini, P. \& Boutin, J. (1987). Variations du régime alimentaire du Hibou grand-duc Bubo bubo en période de reproduction en Basse-Provence. Rer. Fv. Ovn. 57: 23-3l.

Bergerhausen, W. \& Willelms, H. (1988). Methodik und Effizienz der Bestandkontrolle einer Population des Uhus (Bubo bubo L.). Chavadviur 24: I7I-187.

Bergier, P. \& Badan, O. (1979). Compléments sur la reproduction du grand-duc Bubo bubo en Provence. Alauda 47: 27I-275.

Blondel, J. \& Badan, O. (1976). La biologie du Hibou grand-duc en Provence. Nor Oireaux 33: I89-219.

Blondel, J. \& Aronson, J. (1999). Biology and wildlife of the Meditevvanean vegion. Oxford: Oxford University Press.
Bochenski, Z. (1960). The diet of the eagle-owl Bubo bubo (L.) in the Pieniny Mts. Acta Zool. Cvacor. 8: 3II-333.

Brown, D. \& Rothery, P. (1978). Randomness and local regularity of points in a plane. Biometvica 65: II5-I22.

Calderón, J., Delibes, M. \& Amores, F. (1980). Ecología y status del Águila real (Aquila chvyraetor L.) en España. I Reunión Ibevoamevicana. Zool. Vevt.: 705-719.

CEFAC (1988). Erolution de la régétation rommitale du Petit Lubevon (1942-1985). Rapport Interne Parc Naturel Régional du Luberon, Apt, France.

Cheylan, G. (1979). Rechevcher ruv l'ovganiration du peuplement de revtébvér d'une montagne méditevvanéenne. $\mathrm{PhD}$ thesis, University Pierre et Marie Curie at Paris.

Choussy, D. (197I). Etude d'une population de grands-ducs Bubo bubo dans le Massif Central. Nor Oireaux 31: 37-56.

Cochet, G. (1999). Statut et éléments de biologie du grand-duc d'Europe Bubo bubo dans le département de l'Ardèche. Alauda 67: 319-322.

Cramp, S. \& Simmons, L. E. L. (1985). Handbook of the bivdr of Euvope, the Middle Eart and Novth Afvica IV. Oxford: Oxford University Press.

Delibes, M. (1980). El lince ibérico. Ecología y comportamiento alimenticios en el Coto Doñana, Huelva. Doñana Acta Vevt.: $17: I-128$.

Delibes, M. \& Hiraldo, F. (1979). The rabbit as prey in the Iberian Mediterranean ecosystem. Pvoceedingr Wovld Lagomovph Confevence: 614-622.

Donázar, J. A. (1987). Geographic variations in the diet of the eagle owls in western Mediterranean Europe. In Biology and conrevration of novthevn fovert owl: rymporium pvoceedingr: 220-224. Geneval Technical Repovt RM-142. Nero, R. W., Clark, R. J., Lnapton, R. J. \& Hamre, R. H. (Eds). USDA, Forest Service: Fort Collins.

Donázar, J. A. (1988). Selección del habitat de nidificación por el Buho real (Bubo bubo) en Navarra. Avdeola 35: 233-245.

Donázar, J. A. (1990). Geographic Variation in Clutch and Brood Size of the Eagle Owl Bubo bubo in the Western Palearctic. J. Ovnit. 131: 439-443.

Donázar, J. A. \& Ceballos, O. (1984). Algunos datos sobre status, distribución y alimentación del Buho real (Bubo bubo) en Navarra. Rapinyaiver Meditevvanir 2: 246-254.

Donázar, J. A., Ceballos, O. \& Leon, C. F. (I989). Factors influencing the distribution and abundance of seven cliffnesting raptors: a multivariate study. In Raptovr in the modevn wovld: 545-552. Meybourg, B.-U. \& Chancellor, R. D. (Eds). Berlin: World Working Group Birds of Prey \& Owls.

Ferrer, M. \& Donázar, J. A. (1996). Density-dependent fecundity by habitat heterogeneity in an increasing population of Spanish Imperial Eagles. Ecology 77: 69-74.

Frey, H. (1973). Zur Ökologie niederösterreichischer Uhupopulationen. Egvetta 16: I-68.

Gallardo, M., Austruy, J. C., Cochet, G., Seriot, J., Neri, F., Torré, J. \& Thibault, J. C. (1987). Gestion des populations de grands rapaces. Rer. Ecol. Tevve Vie 4: 24I-252.

Garzón, J., Gonzáles, L. M., Gonzáles, J. L. \& Hiraldo, F. (1984). Situación actual y problemática del águila imperial ibérica (Aquila adalbevti Brehm, 186I) en España. Rapinyaiver Meditevvanir 2: 60-69.

Géroudet, P. (1946-57). La rie der Oireaux 1-6. Paris: Delachaux et Niestlé S.A.

Gerrodette, T. (1987). A power analysis for detecting trends. Ecology 68: I364-1372.

Glutz Von Blotzheim, U. N. \& Bauer, L. M. (1980). Handbuch dev Vögel Mitteleuvopar 9. Wiesbaden: AULA-Verlag.

Herrera, C. M. \& Hiraldo, F. (1976). Food-niche and trophic relationship among European owls. Ovnir tcand. 7: 29-4l.

Lamil, A. C. \& Sargent, T. D. (198I). Fovaging behariov. ecological, ethological and prychological appvoacher. New York: Garland STPM Press. 
Lamil, A. C., Lrebs, J. R. \& Pulliam, H. R. (Eds). 1987. Fovaging behariov. New York: Plenum Press.

Lranz, P. (I97I). Nagot om berguvens aktivitat och foda. Faglav i tovmland 4: I3-23.

Lrebs, C. J. (I99I). The experimental paradigm and long-term population studies. Ibir 133(Suppl.I): 3-8.

Leditznig, C. (1992). Telemetric study in the eagle owl (Bubo bubo) in the foreland of the Alps in Lower Austria - methods and first results. Egvetta 35: 69-72.

Leditznig, C. (1996). Habitatwahl des Uhus (Bubo bubo) im Südwesten Niederösterreichs und in den donaunahen Gebieten des Mühlviertels auf Basis radiotelemetrischer Untersuchungen. Abh. Zool.-Bot. Ger. Örtevveich 29: 47-68.

Magurran, A. E. (1988). Ecological direvrity and itr mearuvement. London: Croom Helm.

Martinez, J. E., Sanchez, M. A., Carmona, D., Sanchez, J. A., Ortuño, A. \& Martinez, R. (1992). The ecology and conservation of the eagle owl Bubo bubo in Murcia, south-east Spain. In The ecology and conrevration of Euvopean owlr: 84-88. Natuve Conrevration No. 5. Gailbraith, C. A., Taylor, I. R. \& Percival, S. (Eds). Peterborough: Joint Nature Conservation Committee, U.L.

Mikkola, H. (1994). Eagle owl. In Bivdr in Euvope: theiv conrevration rtatur: 326-327. BivdLife Conrevration tevier No.3. Tucker, G. M. \& Heath, M. F. (Eds). Cambridge: Birdlife International.

Mysterud, I. \& Dunker, H. (1982). Food and nesting ecology of the eagle owl, Bubo bubo (L.), in four neighbouring territories in southern Norway. twed. Wildl. Rer.(Viltvery) 12.

Naveh, Z. \& Lieberman, A. (1994). Landrcape ecology. Theovy and application. 2nd edn. New York: Springer Verlag.

Newton I., Marquiss, M., Weir, D. N. \& Moss, D. (1977). Spacing of sparrowhawk nesting territories. J. Anim. Ecol. 46: 425-44I.

Norusis, M. (1993). tPtt adranced rtatirticr. New York: McGraw-Hill.

Obuch, J. \& Rybin, S. N. (1993). Food of the eagle owl (Bubo bubo Zaissanensis Chachlov) in southern Lirghizia (Osh district). Folia Zool. 42: 19-3I.

Olsson, V. (1979). Studies on a population of eagle owls, Bubo bubo (L.), in southwest Sweden. twed. Wildl. Rer. (Viltvery) 11: I-99.

Orsini, P. (1985). Le régime alimentaire du Hibou grand-duc Bubo bubo en Provence. Alauda 53: II-28.

Penteriani, V. (1996). The eagle owl. Bologna: Calderini-Edagricole (in Italian).

Penteriani, V. (1997). Long-term study of a goshawk breeding population on a mediterranean mountain (Abruzzi Apennines, Central Italy): density, breeding performances and diet. J. Raptov Rer. 31: 308-312.

Penteriani, V. \& Pinchera, F. (199la). II metodo del playback e dell'ascolto sistematico nel censimento di una popolazione di
Gufo reale, Bubo bubo. In Atti II teminavio italiano Cenrimenti Faunirtici dei Vevtebvati. Fasola, M. (Ed.). Ric. Biol. telraggina tuppl. XVI: 385-388.

Penteriani, V. \& Pinchera, F. (I99lb). Censimento del Gufo reale, Bubo bubo, in un'area dell'Appennino abruzzese. Rir. ital. Ovnitol. 60: II9-128.

Penteriani, V., Gallardo, M. \& Cazassus, H. (2000). Diurnal vocal activity of young eagle owls and its implications in detecting occupied nests. J. Raptov Rer. 34: 232-235.

Penteriani, V., Gallardo, M., Roche, P. \& Cazassus, H. (200l). Effects of landscape spatial structure and composition on the settlement of the eagle owl Bubo bubo in a mediterranean habitat. Avdea 89: 331-340.

Pierrotti, R. \& Annett, C. (1987). Reproductive consequences of dietary specialization and switching in an ecological generalist. In Fovaging behariov: 417-442. Lamil, A. C., Lrebs, J. R. \& Pulliam, H. R. (Eds). New York: Plenum Press.

Purroy, F. J. (1974). Fauna naravva en peligvo de extinción. Pamplona: Ediciones y Libros.

Rice, W. R. (1989). Analyzing tables of statistical tests. Erolution 43: 223-225.

Rosenberg, L. V. \& Cooper, R. J. (1990). Approaches to avian diet analysis. ttud. Arian Biol. 13: 80-90.

Schoener, T. W. (197I). Theory of feeding strategies. Annu. Rer. Ecol. tyrt. 2: 369-404.

Seriot, J. (1987). Statut et biologie de trois espèces de grands rapaces rupestres dans le Parc Naturel Régional du Haut Languedoc (aigle royal, aigle de Bonelli et hibou grand duc). Rappovt intevpavcr-tRETIE, France: I9-29.

SIG Luberon. (2000). Etude diachvonique de la regetation du marrif du Petit Lubevon á pavtiv der photor aévienner de 1944 á 1988. Rapport Interne Parc Naturel Régional du LuberonNatura 2000, Apt, France.

Simeonov, S., Milchev, B. \& Boev, Z. (1998). Study of the eagle owl (Bubo bubo L.) (Aves: Strigiformes) in the Strandzha Mountain (southeast Bulgaria). II. Food spectrum and trophic specialization. Acta Zool. Bulg. 50: 87-I00.

Simmons, R. E., Avery, D. M. \& Avery, G. (199I). Biases in diets determined from pellets and remains: correction factors for a mammal and bird-eating raptor. J. Raptov Rer. 25: 63-67.

Sokal, R. R. \& Rohlf, F. J. (1995). Biometvy, the pvincipler and pvactice of rtatirticr in biological vereavch. 3rd Edn. New York: Freeman.

Steenhof, L. (1987). Assessing raptor reproductive success and productivity. In Raptov management techniquer manual: 157170. Giron Pendleton, B. A., Millsap, B. A., Cline, L. W. \& Bird, D. M. (Eds). Washington, DC: National Wildlife Federation.

Valverde, J. A. (1967). Estructura de una comunidad mediterránea de vertebrados terrestres. Madrid: I Monografa de la Estación Biológica de Doñana, C.S.I.C.

Voous, L. H. (1988). Owlr of the Novthevn Hemirpheve. London: Collins. 